\title{
Clinical remission off medication in greek adults with juvenile idiopathic arthritis during a 17 year follow-up period
}

\author{
Despoina Dimopoulou', Maria Trachana ${ }^{2 *}$, Polyxeni Pratsidou-Gertsi ${ }^{2}$, Prodromos Sidiropoulos $^{3}$, \\ Athina Theodoridou', Foteini Lada ${ }^{1}$, Alexandros Garyphallos ${ }^{1}$ \\ From 21st European Pediatric Rheumatology (PReS) Congress \\ Belgrade, Serbia. 17-21 September 2014
}

\section{Introduction}

Clinical remission off medication (CR) in patients with Juvenile Idiopathic Arthritis (JIA) is the optimal aim of treat -to -target strategies. No relevant data have been published for Greek young adults so far.

\section{Objectives}

To assess the achievement of CR and identify CR's predictors in adults with JIA over a-long-term disease course.

\section{Methods}

JIA patients $\geq 18$ years, and a $\geq 5$ years disease duration were enrolled in this longitudinal retrospective cohort study. Radiographic damage was based on total modified Sharp/van der Heijde score (TmSvdHS), articular and extra-articular damage on JADI and physical ability on HAQ-DI.

\section{Results}

98 patients (69 females) with a mean age at disease onset of 7.8 years, an interval from onset to last visit of 17.1 years and a current age of 24.9 years were studied. $37.8 \%$ achieved $\geq 1$ episode of $C R$ and $21.6 \% \geq 2$. The 7 JIA subtypes differed in respect to $C R$ attainment $(p=0.008)$, the worst being patients with polyarthritis RF positive $(0 \%)$ and the best those with persistent oligoarthritis (87.5\%). In $51.4 \%$ of them CR lasted for $\geq 5$ years. Gender, age at disease onset, ANA and anti-CCP positivity were not correlated with CR. CR duration was significantly correlated with lower JADI-A $(\mathrm{p}=0.008)$, JADI-E $(\mathrm{p}<0.001)$, TmSvdHS ( $\mathrm{p}=0.002)$ and HAQ-DI $(\mathrm{p}=0.018)$, while predictors of shorter CR state were polyarticular subtype $(p=0.004)$ and longer duration of disease activity within the first 5 years $(\mathrm{p}=0.001)$.

\section{Conclusion}

Shrinking of disease activity periods in long-term JIA induced by improved treatments leads to extended CR periods and avoids structural damage and physical disability.

\section{Disclosure of interest}

None declared.

\section{Authors' details}

${ }^{1} 4$ th Dept of Internal Medicine, Aristotle University of Thessaloniki, Hippokration Hospital, Thessaloniki, Greece. ${ }^{2} 1$ st Dept of Pediatrics, Aristotle University of Thessaloniki, Pediatric Immunology and Rheumatology Referral Center, Hippokration Hospital, Thessaloniki, Greece. ${ }^{3}$ Dept of Rheumatology, University of Heraklion, Heraklion, Greece.

Published: 17 September 2014

doi:10.1186/1546-0096-12-S1-P152

Cite this article as: Dimopoulou et al: Clinical remission off medication in greek adults with juvenile idiopathic arthritis during a 17 year followup period. Pediatric Rheumatology 2014 12(Suppl 1):P152.

\footnotetext{
${ }^{2}$ 1st Dept of Pediatrics, Aristotle University of Thessaloniki, Pediatric Immunology and Rheumatology Referral Center, Hippokration Hospital, Thessaloniki, Greece

Full list of author information is available at the end of the article
} 